\title{
Complications in body contouring stratified according to weight loss method
}

\author{
Matthew D Chetta MD¹, Oluseyi Aliu MD¹, Bao Anh Patrick Tran MD², Mariam Abdulghani BSc ${ }^{3}$, \\ Kelly M Kidwell PhD ${ }^{4}$, Adeyiza O Momoh MD
}

\begin{abstract}
MD Chetta, O Aliu, BAP Tran, M Abdulghani, KM Kidwell, AO Momoh. Complications in body contouring stratified according to weight loss method. Plast Surg 2016;24(2):103-106.
\end{abstract}

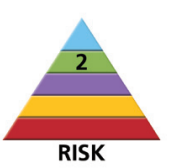

BACKGROUND: Body contouring procedures following massive weight loss have become increasingly common and, unfortunately, continue to be associated with a high complication rate.

OBJECTIVE: To evaluate how weight loss method affects complications following abdominally based body contouring procedures.

METHODS: Patients undergoing abdominally based contouring procedures were retrospectively evaluated over an 11-year period and stratified into two groups based on method of weight loss: diet and exercise; or bariatric surgery. Complications, including seroma, wound dehiscence, skin necrosis, infection, hematoma and venous thromboembolism, were included if they required intervention. An adjusted logistic model was used to examine the effect of weight loss method on aggregate complication rates.

RESULTS: A total of 307 patients were included: 77 (25\%) lost weight through diet and exercise; and 230 (75\%) through bariatric surgery. Results from the logistic model showed no difference in complication rates between weight loss methods (OR 1.01 [95\% CI 0.51 to 2.02]). However, there was a strong correlation between body mass index at the time of surgery and complication rates (OR 1.05 [95\% CI 1.02 to 1.08 ]; $\mathrm{P}<0.01$ ). CONCLUSIONS: The findings reveal no difference in complication rates following abdominal body contouring procedures attributable to method of weight loss. Rather, there was a proportional rise in complication rates in patients with a higher body mass index at the time of surgery. Surgeons and patients should be aware of this trend, and it should be part of any discussion of abdominal body contouring procedures and informing patients of their risk profile.

Key Words: Abdominoplasty; Bariatric surgery; Body contouring; Complications; Panniculectomy; Weight loss

$\mathrm{T}$ he prevalence of obesity in the United States has steadily risen, with more than one-third (36\%) of adults classified as obese (1). Along with this trend, there has been a concomitant increase in the number of bariatric procedures performed for weight loss, with an estimated 179,000 bariatric procedures performed in 2013 (2,3). Many patients achieve massive weight loss (MWL) through lifestyle modifications, typically diet and exercise. Many patients who achieve MWL through surgical means or by lifestyle modifications are left with soft tissue redundancy, which leads to a host of problems including unacceptable cosmesis, pain, intertrigo, difficulty with hygiene and limitations with aerobic exercise $(4,5)$.

Body contouring procedures address the issues associated with soft tissue redundancy after weight loss. Use of these procedures has risen over the past decade, paralleling the rate of bariatric procedures (6). Unfortunately, body contouring procedures are associated with a high

\section{Les complications du remodelage de l'abdomen stratifiées selon la méthode de perte de poids}

HISTORIQUE : Les interventions de remodelage du corps après une perte de poids massive sont de plus en plus courantes. Malheureusement, elles continuent d'être associées à un taux de complication élevé.

OBJECTIF : Évaluer l'influence de la méthode de perte de poids sur les complications après des interventions de remodelage de l'abdomen.

MÉTHODOLOGIE : Les chercheurs ont fait l'évaluation rétrospective de patients qui avaient subi des interventions de remodelage sur une période de 11 ans et les ont stratifiés en deux groupes, selon la méthode de perte de poids : régime et exercice ou chirurgie bariatrique. Ils ont inclus les complications qui avaient nécessité une intervention, y compris le sérome, la déhiscence de la plaie, la nécrose cutanée, l'infection, l'hématome et la thromboembolie veineuse. Ils ont utilisé un modèle logistique rajusté pour examiner l'effet de la méthode de perte de poids sur les taux de complication globaux.

RÉSULTATS : Au total, 307 patients ont été inclus dans l'étude, dont 77 ( $25 \%)$ ont perdu du poids par suite d'un régime et d'exercice et 230 (75\%) après une chirurgie bariatrique. Les résultats du modèle logistique n'ont révélé aucune différence dans les taux de complications selon la méthode de perte de poids (RC 1,01 [95\% IC 0,51 à 2,02]). Cependant, ils ont constaté une forte corrélation entre l'indice de masse corporelle au moment de l'opération et les taux de complications (RC 1,05 [95 \% IC $1,02$ à 1,08$] ; \mathrm{P}<0,01)$.

CONCLUSIONS : Les résultats n'ont révélé aucune différence dans les taux de complication attribuables à la méthode de perte de poids après des interventions de remodelage abdominal. Ils ont plutôt démontré une augmentation proportionnelle des taux de complication chez les patients dont l'indice de masse corporelle était plus élevé lors de l'opération. Les chirurgiens et les patients devraient connaitre cette tendance, qu'il faudrait intégrer aux discussions sur les interventions de remodelage abdominal et à l'information aux patients sur leur profil de risque.

\footnotetext{
${ }^{1}$ Section of Plastic Surgery, Department of Surgery, University of Michigan Health System, Ann Arbor, Michigan; ${ }^{2}$ Division of Plastic Surgery, Department of Surgery, Indiana University School of Medicine, Indianapolis, Indiana; ${ }^{3}$ Section of Plastic Surgery, Department of Surgery, University of Michigan Health System; ${ }^{4}$ Department of Biostatistics, University of Michigan; ${ }^{5}$ Section of Plastic Surgery, Department of Surgery, University of Michigan Health System, Ann Arbor, Michigan, USA

Correspondence: Dr Matthew Chetta, Department of Plastic Surgery, Stanford University, 770 Welch Road, Suite 400, Palo Alto, California 95134, USA. Telephone 650-723-5824, fax 650-725-6605, e-mail mchetta@stanford.edu
} 
TABLE 1

Patient demographics and clinical characteristics

\begin{tabular}{lcc}
\hline Characteristic & $\begin{array}{c}\text { Diet/exercise } \\
(\mathbf{n}=\mathbf{7 7})\end{array}$ & $\begin{array}{c}\text { Bariatric surgery } \\
(\mathbf{n = 2 3 0 )}\end{array}$ \\
\hline With complication & 32.5 & 31.3 \\
Age, years & $45.4 \pm 12.0$ & $46.6 \pm 10.5$ \\
Current body mass index, $\mathrm{kg} / \mathrm{m}^{2}$ & $33.2 \pm 10.5$ & $33.0 \pm 7.7$ \\
Complications & $0.4 \pm 0.5$ & $0.4 \pm 0.7$ \\
Female sex & 76.6 & 83.5 \\
Procedure & & \\
$\quad$ Panniculectomy only & 85.7 & 84.4 \\
$\quad$ + Vertical wedge & 14.3 & 15.6 \\
Additional procedure & 28.6 & 43.5 \\
Smoker & 2.6 & 5.7 \\
Diabetic & 26.0 & 18.3 \\
\hline
\end{tabular}

Data presented as \% or mean $\pm S D$

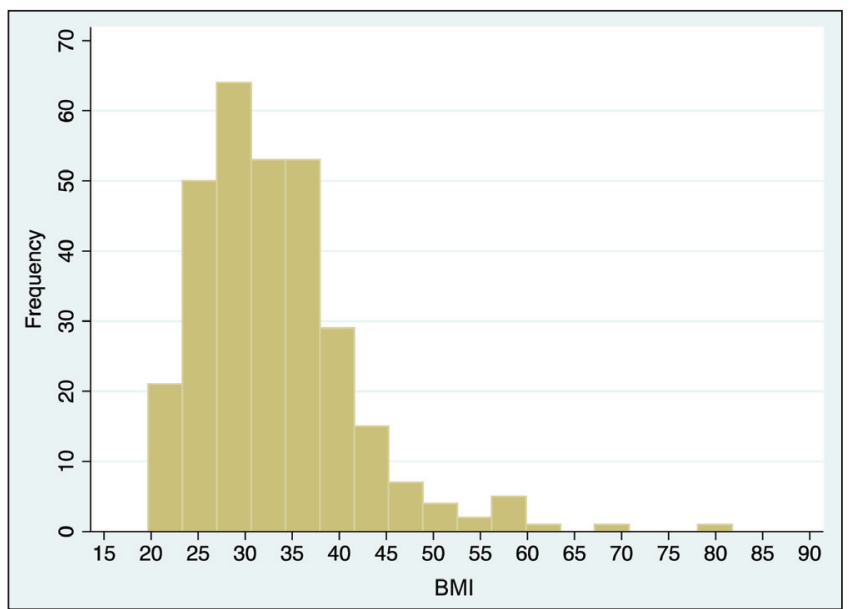

Figure 1) Distribution of patients' body mass index (BMI $\left.\left[\mathrm{kg} / \mathrm{m}^{2}\right]\right)$ at time of body contouring operation

\section{METHODS}

Patients who underwent abdominal contouring procedures between January 1, 2003 and December 31, 2013 at the University of Michigan (Ann Arbor, USA) were identified. Current Procedural Terminology codes 15830 (panniculectomy), 15847 (excision of excess abdominal skin), 15834 (contouring of the hip) and 15835 (contouring of the buttocks) were used to identify 307 consecutive patients who comprised the study population.

Inclusion criteria were age $>18$ years and weight loss of $\geq 50$ pounds $(22.7 \mathrm{~kg})$. Patient demographics, comorbidities and clinical outcomes were evaluated from hospital and office records. Characteristics, comorbidities and potential risk factors that comprised the adjustment variables included age, diabetes, tobacco use, body mass index (BMI) at time of surgery, type of procedure (panniculectomy with or without anterior wedge resection), and additional procedures performed in addition to abdominally based body contouring. The key predictor variable was the method of weight loss: diet and exercise versus bariatric surgery. The outcome variable was the aggregate of postoperative complications that warranted intervention or required a higher level of monitoring or additional therapies. Postoperative complications that counted toward the aggregate included the following: seroma or hematoma requiring evacuation; dehiscence or necrosis requiring additional wound care or debridement; infection requiring oral or intravenous antibiotic therapy or operative drainage of infected fluid collection; and venous thromboembolism requiring anticoagulation. Aggregate postoperative complications were used because the rates of individual complications were too low to permit meaningful analyses.

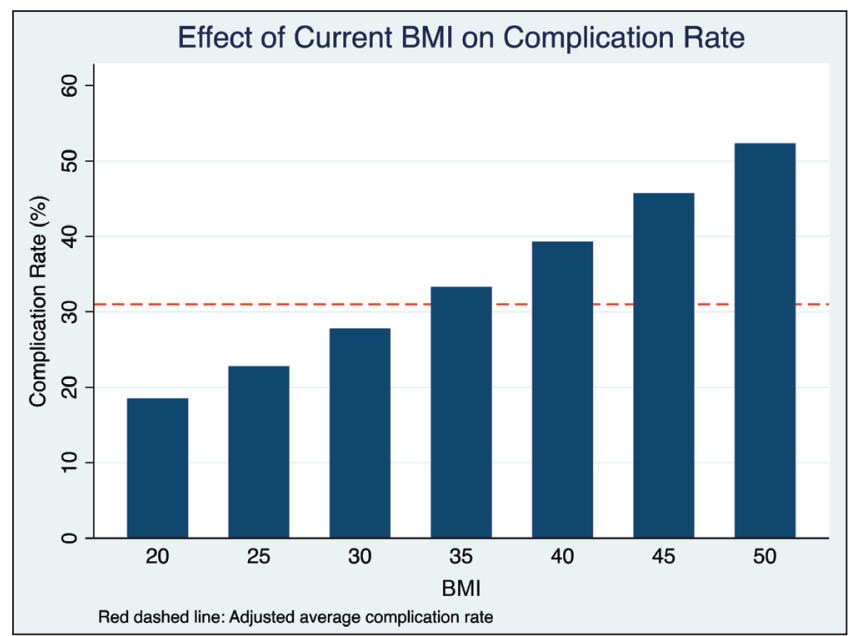

Figure 2) Effect of current body mass index (BMI $\left[\mathrm{kg} / \mathrm{m}^{2}\right]$ ) on complication rate

Descriptive statistics were used to characterize diet/exercise and bariatric surgery patients based on demographics, comorbidities and individual complications (Table 1, Figure 1). An adjusted logistic model was used to examine the effect of weight loss method on aggregate complication rates. The logistic model also adjusted for the effect of patients being clustered under surgeons. Finally, predictive probabilities of complication rates based on BMI at the time of surgery were calculated (Figure 2). The Institutional Review Board at the University of Michigan approved the present study.

\section{RESULTS}

Of the 307 patients included in the study, 77 (25\%) lost weight through diet and exercise, and 230 (75\%) lost weight through bariatric surgery. Patient characteristics according to weight loss type are summarized in Table 1. Results from the logistic model (Table 2) demonstrated no difference in overall complication rates attributable to weight loss method (OR 1.01 [95\% CI 0.51 to 2.02]). However, BMI at the time of surgery had a significant effect on complication rates (OR 1.05 [95\% CI 1.02 to 1.08]; $\mathrm{P}<0.01$ ). Additionally, probabilities predicted from the logistic model showed that complication rates increased in proportion to BMI; patients with $\mathrm{BMI} \geq 35 \mathrm{~kg} / \mathrm{m}^{2}$ had complication rates greater than the study average rate (30.9\%) (Figure 2, Table 3).

\section{DISCUSSION}

Body contouring procedures after MWL carry a high risk for complications $(5,7)$. Understanding factors that contribute to increased morbidity is important to guide interventions aimed at improving outcomes. Our findings show no significant difference in complication rates in patients who lost weight as a result of a bariatric surgery compared with those who lost weight from diet and exercise. Rather, complication rates tended to correlate with BMI at the time of surgery. The results demonstrated that a higher BMI carried a higher complication rate, with a $5 \%$ increase in the risk for complications for each additional BMI point (Figure 2).

Previous studies have sought to assess outcomes in contouring procedures in the MWL population stratified according to method used to achieve weight loss. However, results have differed, with some reporting a difference in complication rates with weight loss achieved after bariatric surgery $(15,16)$, while others found no difference compared with weight loss achieved through lifestyle modifications $(17,18)$. Part of the reason for this focus on weight loss method is based on results from studies comparing restrictive to malabsorptive surgical approaches, which suggest that patients who undergo bariatric surgery have an altered digestive physiology (8) as well as deficiencies in various nutritional markers (9), although the significance of these deficiencies has not been fully explored. Surgery increases the protein-calorie demand by as much 
TABLE 2

\section{Effect of weight loss method, demographics and comorbidities on complication rates}

\begin{tabular}{lcc}
\hline & OR $(95 \%$ Cl) & P \\
\hline Weight loss method & - & \\
$\quad$ Diet/exercise & $1.01(0.51-2.02)$ & 0.96 \\
$\quad$ Bariatric surgery & $1.01(1.00-1.01)$ & 0.13 \\
Age & - & - \\
Sex & - & \\
Procedure type & $0.77(0.50-1.18)$ & 0.23 \\
$\quad$ Panniculectomy only & & \\
+ Vertical wedge & - & \\
Additional procedure & - & 0.01 \\
$\quad$ No & $0.71(0.55-0.92)$ & - \\
$\quad$ Yes & - & \\
Smoking* & - & \\
Diabetes & $1.15(0.65-2.04)$ & 0.63 \\
$\quad$ No & $1.05(1.02-1.08)$ & $<0.01$ \\
$\quad$ Yes & & \\
Current body mass index &
\end{tabular}

*Unable to determine OR for sex or smoking status because all smokers and all male patients experienced complications

as $25 \%(19-20)$ and, with marginal nutrient reserves, the added physiological requirements introduced by a surgical procedure could shift the reserves into a relatively deficient state leading to impaired wound healing and increased complication rates.

Unfortunately, results from studies comparing body contouring procedures following MWL are difficult to interpret because many of them compare a heterogeneous group of contouring procedures comparing different body sites such as brachioplasty, mastopexy, abdominoplasty and thighplasty $(7,11-14)$. Another limitation to most of these studies is the generally low number of subjects in the diet and exercise weight loss category, with groups ranging from as low as 10 to as high as $29(7.2 \%$ and $6.5 \%$ of their study cohorts, respectively) - essentially too few to perform meaningful adjusted analyses $(11,14)$. Despite these limitations, a common observation is that performing contouring procedures at a higher BMI leads to a higher risk for complications (1214,21 ), which is consistent with the results of our study.

The average complication rate for the entire study population was $30.9 \%$. Patients with BMI $>35 \mathrm{~kg} / \mathrm{m}^{2}$ at the time of body contouring surgery surpassed the average complication rate (Figure 2). This trend is consistent with previous studies. Arthurs et al (22) found that patients undergoing panniculectomy after MWL had three times higher risk for wound complications if their BMI was $>25 \mathrm{~kg} / \mathrm{m}^{2}$. Similarly, Vastine et al (17) observed a direct significant adverse effect on abdominoplasty outcomes when patients were obese at the time of contouring surgery compared with borderline or nonobese patients.

\section{REFERENCES}

1. Adult obesity facts. < www.cdc.gov/obesity/data/adult.html> (Accessed December 15, 2013).

2. Santry HP, Gillen DL, Lauderdale DS. Trends in bariatric surgical procedures. JAMA 2005;294:1909-17.

3. American Society for Metabolic and Bariatric Surgery. <http://asmbs.org/2014/03/estimate-of-bariatric-surgery-numbers> (Accessed April 10, 2014).

4. Gloy VL, Briel M, Bhatt DL, et al. Bariatric surgery versus nonsurgical treatment for obesity: A systematic review and metaanalysis of randomised controlled trials. BMJ 2013;347:f5934

5. Strauch B, Herman C, Rohde C, et al. Mid-body contouring in the post-bariatric surgery patient. Plast Reconstr Surg 2006;117:2200.

6. Plastic surgery statistics report. <www.plasticsurgery.org/Documents/ news-resources/statistics/2012-Plastic-Surgery-Statistics/full-plasticsurgery-statistics-report.pdf> (Accessed December 15, 2013).

7. Aly AS, Cram AE, Chao M, et al. Belt lipectomy for circumferential truncal excess: The University of Iowa experience. Plast Reconstr Surg 2003;111:398
TABLE 3

Predictive probabilities of complication rates based on body mass index

\begin{tabular}{lc}
\hline Body mass index, $\mathbf{k g} / \mathbf{m}^{\mathbf{2}}$ & Complication rate, $\%$ \\
\hline 20 & 18.5 \\
25 & 22.8 \\
30 & 27.8 \\
35 & 33.3 \\
40 & 39.3 \\
45 & 45.7 \\
50 & 52.3 \\
\hline
\end{tabular}

This observation was independent of method of weight loss. Other studies have also correlated higher BMI to greater risk for complications (12,23). These studies, along with our data, support the concept that BMI at the time of contouring procedures has a more direct effect on postoperative outcomes than method of weight loss.

The present study had several limitations. First, although our overall complication rate was $30.9 \%$, complication rates in the individual categories were relatively low, making meaningful analysis difficult if assessed separately. Additionally, patients in the diet and exercise group represent only $25 \%$ of the overall study sample. Due to this relatively small population, event rates of individual complications were low, especially for seroma, necrosis, deep vein thrombosis and hematoma, making it difficult to have sufficient power to detect differences in the rates of these complications between the groups. Finally, the study population represented the experience from a single institution and our findings should be generalized with caution.

Despite these limitations, our study provides evidence of a strong correlation between BMI and aggregate complication rates in MWL patients undergoing body-contouring procedures. Additionally, the study adds to the growing body evidence that weight loss method does not appear to influence complication rates in these patients.

\section{CONCLUSIONS}

Contouring procedures have the potential to dramatically improve quality of life in patients who have experienced MWL. Our findings reveal a proportional rise in complication rates in patients with higher BMI at the time of their contouring procedure following MWL. Surgeons and patients should be aware of this trend and it should be part of any discussion of abdominal body contouring procedures and informing patients of their risk profile. Lowering BMI to decrease postoperative complication risk must, however, be balanced against the loss of productivity and quality of life MWL patients experience.

DISCLOSURES: The authors have no financial disclosures or conflicts of interest to declare.

8. Hng KN, Ang YS. Overview of bariatric surgery for the physician. Clin Med 2012:12:435-40.

9. Naghshineh N, O'Brien Coon D, McTigue K, Courcoulas AP, Fernstrom M, Rubin JP. Nutritional assessment of bariatric surgery patients presenting for plastic surgery: A prospective analysis. Plast Reconstr Surg 2010;126:602-10.

10. Constantine RS, Davis KE, Kenkel JM. The effect of massive weight loss status, amount of weight loss, and method of weight loss on body contouring outcomes. Aesthet Surg J 2014;34:578-83.

11. Shermak MA, Chang D, Magnuson TH, et al. An outcomes analysis of patients undergoing body contouring surgery after massive weight loss. Plast Reconstr Surg 118:1026,2006.

12. Nemerofsky RB, Oliak DA, Capella JF. Body lift: An account of 200 consecutive cases in the massive weight loss patient. Plast Reconstr Surg 2006;117:414.

13. Gusenoff JA, Coon D, Rubin JP. Brachioplasty and concomitant procedures after massive weight loss: A statistical analysis from a prospective registry. Plast Reconstr Surg 2008;122:595-603. 
14. Gusenoff JA, Coon D, Rubin JP. Implication of weight loss method in body contouring outcomes. Plast Reconstr Surg 123:373,2009.

15. Greco JA, Castaldo ET, Nanney LB, et al. The effect of weight loss surgery and body mass index on wound complications after abdominal contouring operations. Ann Plast Surg 2008;61:235-42.

16. Staalesen T, Olsén MF, Elander A. Complications of abdominoplasty after weight loss as a result of bariatric surgery or dieting/postpregnancy. J Plast Surg Hand Surg 2012;46:416-20.

17. Vastine VL, Morgan RF, Williams GS, et al. Wound complications of abdominoplasty in obese patients. Ann Plast Surg 1999;42:34-9.

18. Kerviler SD, Hüsler R, Banic A, Constantinescu MA. Body contouring surgery following bariatric surgery and dietetically induced massive weight reduction: A risk analysis. Obes Surg 2009;19:553-9.
19. Williams JZ, Barbul A. Nutrition and wound healing. Surg Clin North Am 2003;83:571-96.

20. Wilmore DW. Metabolic response to severe surgical illness: Overview. World J Surg 2000;24:705-11.

21. Chong T, Coon D, Toy J, Purnell C, Michaels J, Rubin JP. Body contouring in the male weight loss population: Assessing gender as a factor in outcomes. Plast Reconstr Surg 2012;130:325e-330e.

22. Arthurs ZM, Cuadrado D, Sohn V, et al. Post-bariatric panniculectomy: Pre-panniculectomy body mass index impacts the complication profile. Am J Surg 2007;193:567-70.

23. Coon D, Gusenoff JA, Kannan N, El Khoudary SR, Naghshineh N, Rubin JP. Body mass and surgical complications in the postbariatric reconstructive patient: Analysis of 511 cases. Ann Surg 2009;249:397-401. 